\title{
Innovation in teaching and learning methods: Integrating sustainability subjects in the architectural design process
}

\author{
Carolina Sepúlveda M. ${ }^{\text {la }}$, Natalia Gajardo H. ${ }^{1}$ \\ ${ }^{1}$ EDP Austral de Chile University, Faculty of Architecture and Arts Institute of Architecture and \\ Urbanism, Campus Isla Teja, IV Región de los Ríos, Valdivia 5090000, Chile
}

\begin{abstract}
Architectural training has always been linked to two opposed and complementary processes: creative thinking and linear/technical thinking. Nowadays, the training process of an architect is usually based on an experimental design studio, which is complemented by the formal teaching of theoretical and technical subjects. This system is based on the idea that it will produce a comprehensive professional who is capable of achieving creative, appropriate and viable solutions. However, this teaching method can carry hidden difficulties that may hinder the development of architecture students to their full potential. This article will inform on the methodology and results of applying an innovative method of teaching and learning architecture. This method aims at maximising the capacity of students to integrate their creative and technical competencies in order to increase the quality of work of future architects.
\end{abstract}

Keywords: architecture; innovation; teaching and learning process; knowledge Integration.

\section{Background}

Learning is primarily understood as the process of transforming information into knowledge and competencies. In the learning process, humans do not behave as a 'copy machine'. On the contrary, when faced with various sources of information and data, we selectively build knowledge and competencies and determine their relative value, [1].

Sustainability and energy efficiency are concepts which until today have been relatively disconnected to curricula for the formation of architects in Chile. It is common to find professional architects who have a rather uncommitted approach to the energy behaviour of a building, the comfort of the people living in it and their relation with the environment. This fact has been described as follows: “...Because of this failure of the architectural

a Corresponding author: carolinasepulveda.m@gmail.com; carolina.sepulveda@uach.cl 
profession -to almost literally- keep its house in order, it fell to another body of men to assume responsibility for the maintenance of decent environmental conditions: everybody from plumbers to consulting engineers. They presented 'another culture' so alien that most architects held it beneath contempt, and still do.", [4].

This definition is still valid today when describing the current reality of the approach of the profession when building the infrastructure we live in.

In recent years concepts such as sustainable architecture, bioclimatic, green architecture are public knowledge, establishing themselves as a requirement for any company offering design and construction services. However it is true that these definitions have not provided real knowledge about the basic needs of comfort and energy efficiency which should be integral part of architectural design and have become a powerful marketing tool.

Architecture and sustainability have been defined in many ways, from a technological, environmental, even sensorial point of view. But the transversal and invariable concept always is "responsible design", where a building or house is more than just a place (to live in); it is part of constructive responsibility with the inhabitant and the environment, [2].

Responsibility starts with those who convey knowledge and educate future architects as agents with the capacity to make decisions from design to politics which are the standards for construction in a city or country. It is the schools of architecture which have the responsibility and capacity to observe, assess, update and innovate their learning and teaching systems in order to respond to the local social, cultural, economic and environmental needs as well as to the growing global energy requirements. Achieving an integration of competences in the professional training and education of architects passes through a series of academic challenges which will lead to future generations of comprehensive, proactive and responsible professionals.

\section{Architecture and sustainability in the academic curriculum}

The research presented here has been developed at the Architecture School of Universidad Austral de Chile (UACh). The work is based on a diagnosis of the teaching of technical subjects related to construction, sustainability and energy efficiency as a complement to design studios. The objective of this diagnosis was to assess the state of the art of the teaching and learning process in order to design a new methodology that would help improve the following areas: the academic performance of students; the development of competencies for self-education; the optimisation of teaching hours; increasing the integration of theoretical and practical variables in the architectural design process; and the inclusion of teaching staff in the planning and improvement of the teaching and learning process.

To achieve this it was important to consider that students have very varied ways of learning and that there is a great diversity in the ways in which information is transformed into knowledge. Students have different origins and cultures; strengths and weaknesses; interests; ambitions; sense of duty; motivation levels; and relationships with learning, [3].

The teaching subject analysed here is titled 'Sustainable Systems'(SS) and was created as the integration of areas related to construction, sustainability and ecology. This integration was aimed at minimising the understanding of different building components (such as construction methods, energy efficiency and sustainability) as disconnected areas of the design process.

The paper focuses on the process of change and innovation in the curriculum of the architecture school. The learning principles underpinning this change and the necessary evaluation methods in relation to the learning context are discussed. 


\section{Innovation in teaching and learning methods}

The process of changing the teaching and learning methodology was developed in six phases, each requiring specific contexts, boundary conditions and evaluation methods. This was done with the participation of all stakeholders involved, including university directives, the teaching staff, students and education professionals. The first phase started by the initiative of the teaching staff that set out to assess the results of the existing teaching methods. With this, the main conditions for a change in the curriculum are prepared, arriving at a collective acknowledgement of the need for a change , [1]. The second phase consists of collecting, revising and systemising information regarding teaching contents, methods, academic results, and subjective perceptions of teaching staff and students in relation to the subjects taught. The third phase consists of elaborating a plan of collective work, diagnosis and analysis of existing problems and opportunities. Phase number four is focused on the design of the new methodology through trans-disciplinary collaboration and the definition of lines of action for its development and application. In phase number five, the new methodology is applied and evaluation methods are designed to collect qualitative and quantitative data used later to assess the results. Finally, in the sixth phase results are collectively analysed and further changes to the methodology are proposed in order to improve it based on the feedback obtained.

The curriculum changes discussed here have been already in operation for four years and have included improvements and permanent adjustments. Although this methodology demands higher levels of coordination and participation from teaching staff, results have surpassed expectations, showing improvements in the motivation levels of both students and teaching staff and in the development of academic competencies. Moreover, from this process it has been possible to obtain various teaching and learning products, such as: books; a web platform for the communication with students; and other didactic tools that aid experimental learning and self-education.

\subsection{Assessment of the existing teaching methods}

The foundation on which the development of this Project is based is the permanent cooperation of a team of 5 teachers in charge of the assessed subjects, who jointly identified the need to innovate the current teaching systems. The project begins with the systematic assessment of existing methodologies and teaching contents by means of socialization meetings where the different experiences of each teacher are discussed.

Description of the subjects:

Architecture studies are divided into three professional training cycles:

- Basic education cycle (1st year)

- Professional training cycle (2nd, 3rd and 4th year)

- Deepening of knowledge cycle (5th year)

Each cycle deals with different perspectives; three relevant aspects for the professional architect have been defined in the profile of graduates: Design, Sustainability - Technology - and Context. By acquiring the competences defined in each cycle students will obtain a comprehensive vision of their potentials, they will understand the society they form part of and in which they will become active. After completing the Deepening of Knowledge cycle students have to develop a Graduation Project, normally at the beginning of the 6th year and lasting one year.

This pedagogical model focuses on problem solving for sustainable development, furthermore including all the main curriculum subjects into a Studio workshop of architectural design, which forms the central part of the curriculum. This may occur by ways of thematic integration or practical workshops, where the contents of the theoretical 
classes are applied to the projects developed in the Studio. This is a dynamic methodology, obliging teaching staff to hold regular coordination meetings in order to develop topics and evaluate results.

Sustainable System courses are present in the first two professional training cycles (from first to fourth year) and are a parallel complement to the Studio workshop, incorporating technical and theoretical variables associated to sustainability and energy efficiency through the understanding of the process of design and the generation of an architecture project.

In order to make these different roles visible, the goals of the subjects are presented in the following:

- Sustainable System 0 Basic Training Cycle 1st year. The student understands the concept of sustainability from a holistic point of view with special emphasis on environmental and cultural aspects. A knowledge base is developed, in order to understand the different variables associated to the built space and its relation to the natural environment.

- Sustainable System I Professional Training Cycle 2nd year. At the end of the course the student is able to distinguish the variables which define habitability and comfort of the built space from the human perspective, making use of appropriate solutions for different situations and environmental conditions.

- Sustainable System II Professional Training Cycle 3rd year. Understand and apply energy efficiency concepts from the architectural perspective, introducing technological solutions within the framework of sustainability to deal with design issues in architectural assignments.

- Sustainable System III Professional Training Cycle 4th year. The student - both in an individual and team context - learns to comprehensively handle and apply sustainability criteria in urban intervention, elaborating strategies based on critical assessment, both from the existing urban model as from proposed models, optimizing economic, social, physical, technological, cultural and environmental resources.

Current situation: Each subject is taught by a professor in charge, who elaborates the program and methodology he or she thinks most appropriate for teaching the contents (teaching based on objectives). In all cases the strategies are mixed: lectures, group work, individual work, exhibitions and field trips. At the end of the academic period of one year, the subject is integrated directly into the workshop process, as the acquired contents form part of the requirements for the workshop project in all the training cycles of the career. Finally, in many cases, the final evaluation of the subject is embedded within the proposals and solutions applied to the architecture or urbanism Project presented. During the next year the students start the next subject with a different professor and a new program

\subsection{Data collection and information systematization of teaching contents, methods, academic results}

The information provided by each professor in charge and their assistants on the Sustainable Systems courses of the years, SS0 (first year), SSI (second year), SSII (third year) and SSIII (fourth year) made it possible to elaborate tools for the assessment of the state of the methodologies and contents of the courses. First the information contained in the programs of the different courses was extracted, and the correlations and number of contents per year were examined. Two matrixes were developed helping to understand the overall performance of the course: 
- Matrix of course objectives according to the years: In this matrix the information of the different years containing a description and the general objective and specific objectives of each yearly program is matched.

- Matrix of course contents: For each year the course is developed based on a list of contents with increased complexity every year. At the same time the contents change according to the development achieved in the architectural design workshop of the career. For a better analysis, different colours were used in order to identify matches per year. Generally speaking each stage of the course is structured according to 4 main topics: the Environment, Sustainable Building, Design and energy calculation and Legislation. Finally all these contents are applied to the architecture project, which is evaluated during the Studio workshop. In the end, what is evaluated is the student's capacity to apply technical contents to the creative process.

With these two matrixes the group of academic staff evaluated the following factors:

- Matching contents from one year to the next.

- Teaching load per year.

- Relevance of contents according to training cycle the students are in.

- Performance, attendance and motivation of the students.

- Discussion of the methodologies applied by each professor in charge of each topic.

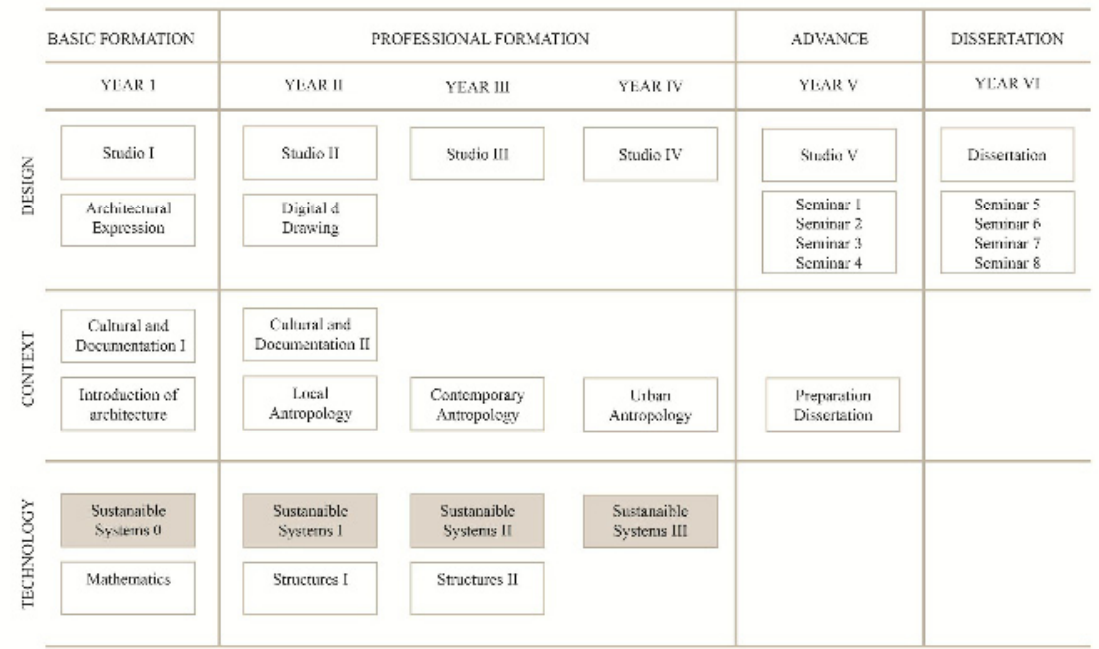

Fig. 1. Curriculum Career of Architecture UACh (http://arquitectura.uach.cl/3_2malla.html 25 Junio 2015)

\subsection{Elaboration of a plan of collective work, diagnosis and analysis of existing problems}

The analysis is based on the information elaborated from the study programs and personal experience of the teachers involved. Some of the challenges found are:

- Repeated contents and lack of continuity in the different courses: The insufficient degree of communication between the teachers leads to isolated courses without feedback from the preceding and following courses, resulting in an excess of class hours spent on contents which eventually do not form the basis for the further development of knowledge in the following year.

- Random methodologies for the different courses, making it extremely complex for the students to understand the logic of what they are studying. Contents are acquired mechanically and not actively. The most widely used methodology among the teaching 
staff is the lecture class, revealing the lack of elements such as experimenting, self-learning and creativeness within the teaching methods applied.

- Lack of specialization of the teaching staff in specific program contents: as the courses are built around the different areas of architecture, construction and sustainability, teachers must provide information on all the areas under circumstances where topics do not necessarily coincide with their specialization. Although the quality of the contents fulfils the course requirements, the situation eventually is unsatisfactory for both the student and the teacher.

Lack of connection between the contents and the workshop: although the course supports the design process of an architectural project, in many cases there was no sufficient coordination for providing competences or contents helping the students when developing their design project.

\subsection{Design of a new methodology through trans-disciplinary collaboration and definition of lines of action}

As a result of the analysis of contents and objectives of the different courses SS0, I, II y III a teaching system was elaborated trying to remedy the deficiencies observed during the first stage of the analysis. The new teaching methodology aims at providing the students with clearly marked tools and competences. For this, in the first year (2012) the idea was presented to the student, explaining and discussing with them the reasons and goals of the initiative.

The design of this methodology consists in elaborating a teaching and learning model divided into teaching units and modules. Each unit corresponds to one of the topics defined in the career which were considered necessary in order to comply with the graduate profile. The previously defined topics corresponding to the units are: Environment, environmental design and energy calculation, construction and legislation. Each unit is assigned a group of teachers to teach the classes according to their specialization. A head teacher for each subject is in charge of the general coordination of the year, making sure that the different modules are correctly, efficiently and timely conveyed by the teachers. At the end of the year a module "Tutorial Workshop" was incorporated, where teachers will assist students to resolve and correct their proposals within the architecture project.

The teacher or teachers in charge of a specific topic elaborated a work plan and contents to be incorporated into the programs and to be taught during the year. Quarterly meetings were held to coordinate and assess the application of the methodology. After completing the first year of applying the new methodology based in study units and modules, the team of teachers will meet again to critically examine the experience.

The new methodology allows for the continuity of each topic (module) throughout the years and stages of each subject, distributing contents in a comprehensive and evolutionary way each year. This way the students can differentiate the topics and their relevance at the moment of switching over to the architecture workshop.

Each module is structured to be applied through active methodologies, promoting selflearning and solving problems proposed by the teacher. To optimize this process, some tools were implemented facilitating the adoption of active methodologies. One of these is a web platform, as communication between students and teachers is fundamental for learning and mutual understanding during the implementation period of the new methodology. This platform provides the material recommended for each year of the course which can be downloaded, as well as links of interest and a data base of projects from the preceding period which can be used as reference material for new students. This platform is centralized and global and accessible for everybody (www.uachsustentable.cl). Also, a model-building centre was incorporated. 
Finally, all the information generated each year is turned into a book with the experiences, works and results of the different courses as register and dissemination tool of the applied contents.

\begin{tabular}{|c|c|c|c|}
\hline 1st year architecture & 2nd year architecture & 3rd year architecture & 4th year architecture \\
\hline $\begin{array}{l}\text { SUSTAINABLE } \\
\text { SYSTEM 0 }\end{array}$ & $\begin{array}{l}\text { SUSTAINABLE } \\
\text { SYSTEM I }\end{array}$ & $\begin{array}{l}\text { SUSTAINABLE } \\
\text { SYSTEM II }\end{array}$ & $\begin{array}{l}\text { SUSTAINABLE } \\
\text { SYSTEM III }\end{array}$ \\
\hline \multicolumn{4}{|c|}{ Module Built environment } \\
\hline Built environment 1 & Built environment 2 & Built environment 3 & Built environment 4 \\
\hline \multicolumn{4}{|c|}{ Module Environmental Design } \\
\hline $\begin{array}{l}\text { Environmental Design } \\
\text { (basic sciences) }\end{array}$ & Environmental Design 1 & Environmental Design 2 & Environmental Design 3 \\
\hline \multicolumn{4}{|c|}{ Module Construction and materials } \\
\hline $\begin{array}{l}\text { Introduction to } \\
\text { construction }\end{array}$ & Construction and materials 1 & Construction and materials 2 & Urban technology \\
\hline \multicolumn{4}{|c|}{ Module National and International sustainability certifications } \\
\hline & Certifications 1 & Certifications 2 & Certifications 3 \\
\hline \multicolumn{4}{|c|}{ Module Sustainable Urbanism } \\
\hline $\begin{array}{l}\text { Introduction to sustainable } \\
\text { urbanism }\end{array}$ & Sustainable Urbanism 1 & Sustainable Urbanism 2 & \\
\hline \multicolumn{4}{|c|}{ Studio assis tance } \\
\hline Studio I & Studio II & Studio III & Studio IV \\
\hline
\end{tabular}

Fig. 2. Units and modules in the second year of methodology application. Prepared by the authors.
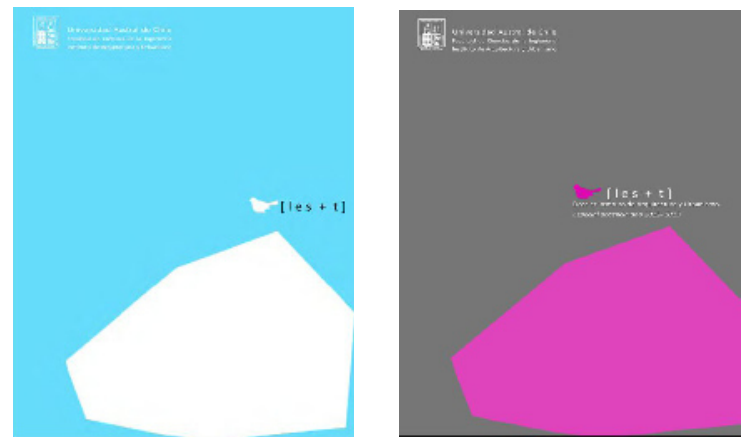

Fig. 3. Annual Sustainable Systems book

\subsection{Application of the new methodology and design evaluation methods to collect qualitative and quantitative data}

As a methodology to understand the effectiveness of the proposal, a survey model was elaborated both for students and teachers taking part in the Sustainable Systems course in the different years of the career. For the elaboration of the survey model cooperation with the Department of Quality Control and Curriculum Innovation (Departamento de Aseguramiento de la Calidad e Innovación Curricular, DACIC) of Universidad Austral de Chile was sought.

The survey applied to the students had the aim to understand the relevance of the course within the academic career, comparing the new module-based teaching system with the traditional system, finding out which modules are more interesting for the student and which modules are more difficult for them. Within the student evaluation process, the design and implementation of a proper evaluation system is a key element to understand if the performance level defined in the course program has been achieved or not , [1]. Another tool of major importance is the creation of a curriculum map, linking the learning results to the acquired competences, assigning responsibilities as competences are being acquired, [1]. 
The survey was applied to approximately 120 students from different levels within the second year of the course based on the module methodology. The results were the following:

- $60 \%$ of the surveyed students believe that the Sustainable Systems course was Very Important for the development of their academic year.

- $65 \%$ of the surveyed students believe that the teaching method by modules and different teachers is Good compared to the traditional system with only one teacher. This indicates that the change of the course format was not difficult for the students.

- The most interesting and/or motivating modules for the students are those related to environmental design, construction, technical application and a new module introduced related to urbanism. The least interesting and/or motivating modules are mostly theoretical modules related to legislation and certification.

- In relation to difficulty, $40 \%$ of the students point out that the most difficult modules are those related to legislation and certification, which at the same time are modules considered less interesting/motivating. The survey also shows that $35 \%$ of the students consider the modules related to environmental design difficult.

- As to the exercises realized during the year, those considered more motivating are the ones involving the elaboration of models or practical exercises as well as group work. The results show that for the students written tests are largely uninteresting.

The survey applied to the teachers in charge of the course aimed at understanding the degree of difficulty of coordinating the modules throughout the year, comparing the module-based teaching method with different teachers to the traditional system with only one teacher, evaluating the performance of the assistantship throughout the academic year, and finally discovering the best teaching methodology to provide and evaluate contents.

The survey was applied to the 9 teachers in charge of teaching the course on the different levels.

The results of the survey were the following:

- Of the 9 teachers surveyed $44,4 \%$ consider that the difficulty of coordinating the modules during the year was Regular, and another $44,4 \%$ consider that the coordination of modules did not imply major difficulties.

- Of the 9 teachers surveyed 54,6\% consider that the module-based teaching method with different teachers is Regular compared to the traditional system with only one teacher, and another $44,4 \%$ consider that the module-based teaching method with different teachers is Excellent compared to the traditional system with only one teacher

- Of the 9 teachers surveyed 44,4\% evaluate the performance of their assistant as Excellent, and another 33,3 \% evaluate the performance of their assistant as Regular.

- Of the 9 teachers surveyed $66,7 \%$ prefer the elaboration of models and practical exercises as methodology for providing and evaluating contents in their modules, and another $22,2 \%$ prefer group presentations as methodology for providing and evaluating contents in their modules.

- Of the 9 teachers surveyed $77,8 \%$ evaluate the performance of their students in the workshop as Good and another 22,8 \% evaluate the performance of their students in the workshop as Regular.

The result of the survey with the participation of students and teachers show that there is a higher degree of motivation when applying active methodologies related to building models. For this reason the project has equipped the LEST laboratory with the necessary infrastructure to increase the number of assignments, works and tasks based on this methodology. 


\subsection{Results are collectively analysed and further changes to the methodology are proposed}

During the process of analysing the results in order to generate future changes in the proposed methodology a series of meetings with the participation of the teachers in charge of the course was held to obtain feedback on the shortfalls and advantages of the methodology in order to accomplish improvements for the next academic year. Coordination and the formation of a team of teachers who closely work together, providing and permanently evaluating all the different teaching activities, are essential , [1].

The following observations were made:

- Analysis of course grades

For the analysis of the results, statistical studies were carried out based on the grades obtained in the course. These statistics made it possible to better understand the development of student grades according to the year and course. The results obtained showed the following: with the new teaching and learning system the number of students repeating the year decreased significantly by $20 \%$, naturally leading to a better course average. The lowest grades of the courses were improved at all levels of the course, improving students' overall average performances.

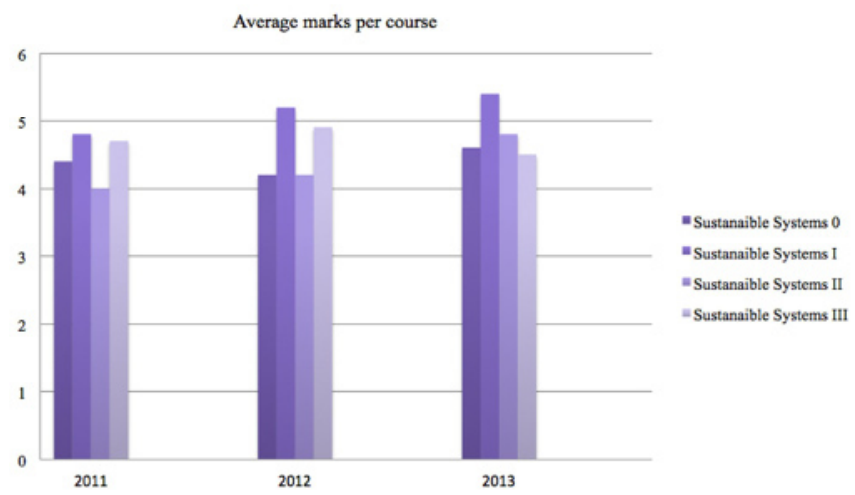

Fig. 4. Number of students passed by year (source: Prepared by the authors).

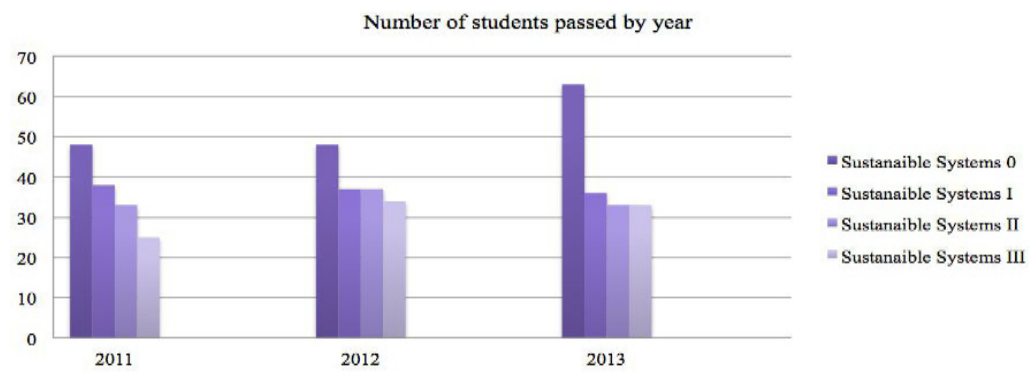

Fig. 5. Number of students passed by year (source: Prepared by the authors).

- Incorporation of the urbanism module: At the end of the first year after implementing the module system, the results were analysed in order to improve performance during the next year. In can be observed that during the first three years of the career the concept of urban sustainability is only insufficiently applied in the Sustainable Systems course. In order to achieve a higher degree of integration between the Studio workshop and 
Sustainable Systems, the urbanism module was created, allowing for better integration as of the first year of the course.

- Coordination among teachers: In order to accomplish correct coordination among the teachers in charge of holding the course, a course coordinator was designated who will develop a schedule of modules with dates and durations together with the teachers before the beginning of each academic year. The coordinator is in charge of making sure that all the deadlines and dates are respected, guaranteeing correct coordination.

\section{Conclusions}

Changing the teaching and learning methodology is a process nourished fundamentally by the amount of information which can be evaluated for the sake of improvements. The value of information is evenly distributed among quantitative records (grades, evaluations, attendance, etc.) and qualitative records. The latter involve the teachers' experience, and elements which often determine the degree of lack of interest, motivation or effectiveness of a course. The project presented represents two years of continuous work in the application of improvements, assessment and constant development. Improvement suggestions were developed at the same time as evaluation tools, leading to a high degree of mutual appreciation between teachers and students. The survey was conducted as a means to measure the success of the module-based system. The results show approval of the module-based teaching and learning system both among teachers and students.

Some of the aspects observed after two years of applying the new methodology.

- Better distribution of the teaching load over the year

- Higher motivation among teachers and students

- Methodology positively received by the Institute of Architecture and Urbanism. The methodology was replicated in other courses complementing the architecture workshop.

- Higher student attendance and better grades (see development goal f)

- More active methodologies providing contents in the course

- Adequate coordination and general commitment of the team of teachers involved in the Project.

To assure the continuity of the initiative it will be necessary to permanently assess contents and methodologies according to the changing needs and demands of the environment and new generations of students, understanding the diversity of human groups wanting to become architects.
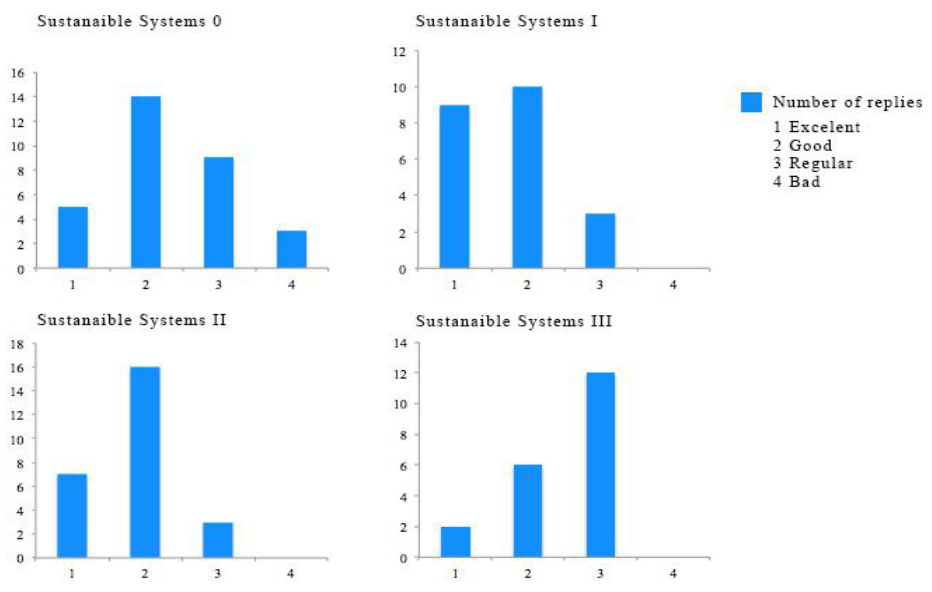

Fig. 6. Results or the survey appıled to students comparıng the module-based teaching system with different teachers to the traditional system 


\section{References}

1. Lachiver, G., Tardif, J., Fostering and managing curriculum change and innovation. 32nd ASEE/IEEE Frontiers in Education Conference. Boston, (2002).

2. Disch, R., Small Eco- houses. Taschen GmbH. Köln.,(2007).

3. Felder, R., Brent, R., Understanding Students Differences. Journal of Engineering Education, 94(1), 57-72, (2005).

4. Banham, R., The Architecture of the Well- tempered Environment (2nd ed.) (p11). London: The Architectural Press, (1984).

5. Heschong, L., Thermal Delight in Architecture. Cambridge, Massachusetts. The MIT press, (1979).

6. Escuela de Arquitectura \& Instituto de Arquitectura y Urbanismo, Universidad Austral de Chile., Malla Curricular. Valdivia. Chile. Arquitectura.uach.cl/3_2malla.html. (2015). 